\title{
Role of the Comforter as an Aetiological Factor in Rampant Caries of the Deciduous Dentition
}

\author{
G. B. WINTER, MARGARET C. HAMILTON ${ }^{\star}$, and P. M. C. JAMES \\ From the Department of Children's Dentistry, Institute of Dental Surgery, Eastman Dental Hospital, and \\ the Department of Preventive Dentistry, Royal Dental Hospital School of Dental Surgery, London
}

This investigation has been stimulated by an apparent increase in the prevalence of rampant caries of the deciduous dentition amongst pre-schoolchildren in the London area.

Although there is little universal agreement on a definition of rampant caries, it may be described as a lesion of acute onset involving many or all of the erupted teeth, rapidly destroying coronal tissue, often on surfaces normally immune to decay, and leading to early involvement of the dental pulp. The acute onset of the disease in the deciduous dentition is a notable feature, and occasionally parents are convinced that the teeth have erupted in a carious state. The initial lesion is usually seen within a short time of eruption on the labial surface of the maxillary incisors, close to the gingival margin, where it presents as an area of whitish decalcification or minimal pitting of the enamel surface. This area soon pigments to a light yellow coloration and at the same time extends in size laterally to the approximal surfaces and downwards to the incisal edge. At a more advanced stage, when the dentine is deeply involved, the carious process will often extend around the entire circumference of the crown, leaving only a small area of sound enamel at the incisal edge. Minimal trauma to the tooth at this stage, a frequent occurrence in the toddler, results in a 'pathological' fracture of the crown. Less commonly, the lesions commence on the palatal surfaces of the maxillary incisors, and, in a particularly florid case, they may decay during tooth emergence, with carious involvement of the incisal edges.

It is this primary manifestation of the condition on the labial surface of the maxillary incisors that has given rise to the descriptive title of 'labial caries' by James, Parfitt, and Falkner (1957). Occasionally, at this stage, the carious process will undergo

Received August 2, 1965.

^ Now at the School of Dental Surgery, Birmingham. partial or complete arrest and in so doing it pigments to a dark brown or black colour. This appearance may have been responsible for the term 'mélanodontie infantile' given to the condition by Beltrami and Romieu (1939).

There can be little doubt, however, that the appearance of labial caries is merely the primary stage of a more widespread disease of the deciduous dentition. The first deciduous molars are the next teeth to be affected, maxillary slightly ahead of mandibular, though simultaneous involvement of incisors and first molars in the upper arch is not uncommon. These lesions may be situated on the occlusal, buccal, or lingual surfaces, where they lead to rapid destruction of the crown. At this stage symptoms frequently supervene, causing parents to seek dental advice, so that the presentation of a young child with gross destruction of all maxillary incisors and four first deciduous molars is a frequent occurrence in paedodontic practice (Fig. 1).

The remainder of the deciduous dentition is usually affected by caries in a fairly constant way, maxillary canines prior to second deciduous molars, and finally mandibular canines and incisors. The dentition is, therefore, affected in the same sequence as that in which the teeth erupt, with the exception of the lower incisors and canines.

In many cases parents fail to realize the significance of the early signs and symptoms of rampant decay, and by the time the child is first seen many of the teeth are beyond restoration. Advanced coronal destruction with pulpal infection and associated chronic abscesses pointing on to the labial or buccal gingiva are common. Such a process may lead to the entire destruction of the deciduous dentition by $2 \frac{1}{2}$ years of age.

Rampant caries of the deciduous dentition has been observed in different population groups for many years, particular emphasis always being given to the involvement of the maxillary incisors. Harries (1911) noted that caries of the upper front 


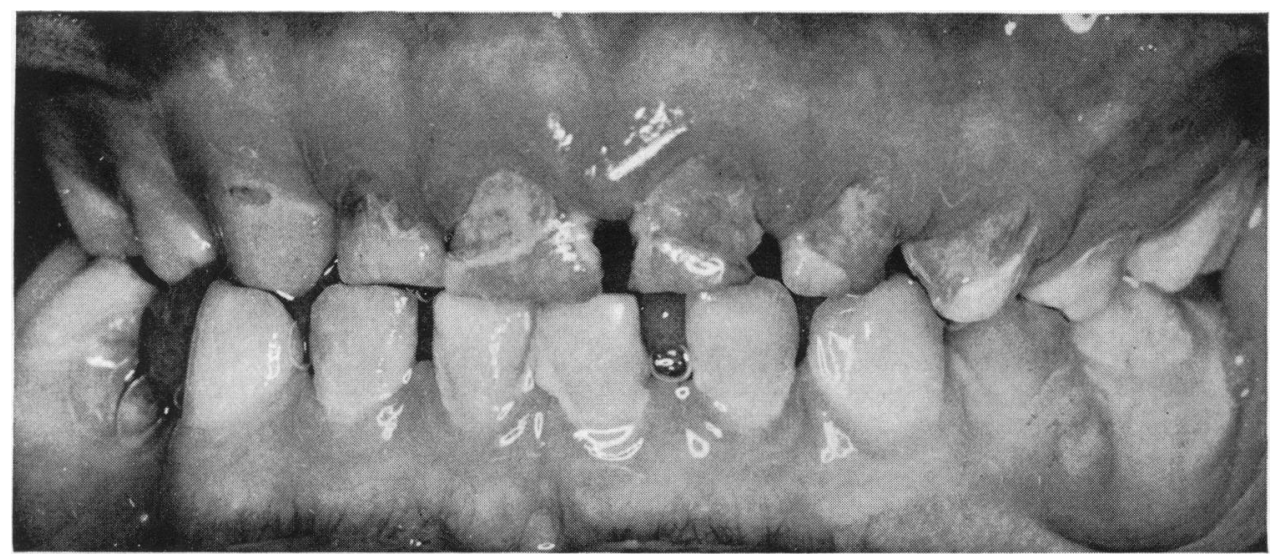

FIG. 1.-Boy aged 4 years showing rampant caries of the maxillary incisors and canines more marked on the left side of the jaw.

teeth appeared to be associated with the sucking of comforters, the fashion at that time being for the rubber 'dummy'. It was Pitts (1927), however, who realized that it was the sweetened coating sometimes placed on the surface of the comforter that was likely to be the main aetiological factor in the causation of the disease. At that time the dummy was commonly dipped in sweetened malt and cod-liver oil extracts, condensed milk, honey, sugar, jam, and aniseed syrup before being given to the child to suck as a pacifier or soporific. Pitts suggested that defective structure of the enamel might be a contributory factor in some cases.

This association between labial caries and sugared comforters has also been observed by Stein (1947) in the U.S.A.; Syrrist and Selander (1953) in Sweden; and James et al. (1957), and Robinson and Naylor (1963) in London. In the two more recent of these studies in London a new fashion in sugared comforters was observed which was beginning to supplant the use of the dipped dummy as a pacifier. One of these was the prolonged use of comforter feeding bottles containing either milk and sugar, fruit juice and sugar, fruit syrup, or sugared water; the other was the introduction of the hollow 'feeder', which has a reservoir behind the teat capable of holding up to $10 \mathrm{ml}$. fluid, and into which parents have been encouraged by the manufacturers to place honey, sugar, or fruit syrups.

Syrrist and Selander (1953) observed that the use of sugared comforters was more prevalent in the lower socio-economic groups, though it occurred throughout the social structure in Sweden.

\section{Subjects and Method}

Two groups of 100 children aged 1-5 years were investigated over an 18-month period in 1963-64. One group contained all children who presented in the Children's Department, Eastman Dental Hospital, with rampant caries. For the purpose of this study rampant caries was defined as a minimum of two maxillary incisor teeth with carious lesions involving the labial or palatal surfaces. The other group consisted of children attending a child welfare centre for a routine medical examination. The latter group, being dentally unselected, acted as a control. The age limits were set by the rarity of caries in the first year and the normal physiological shedding of deciduous teeth in the sixth year, which makes it difficult to obtain an accurate assessment of the number of teeth extracted after the fifth birthday.

The two groups were of a similar socio-economic structure. The majority of children in both came from families at the lower end of the socio-economic scale (Groups III, IV, and V of the Registrar-General's classification) and they both contained small numbers of recent immigrant children.

Only two observers were employed throughout the study (G.B.W. and M.C.H.). All the children were seen in the presence of the mother, from whom information was obtained to complete a questionnaire before the examination of the mouth. This consisted of a printed form which was designed to be as comprehensive as possible and to cover all the aetiological factors thought to be significant (Fig. 2).

It was realized that some information obtained from the parent by an interview of this nature was likely to be unreliable, especially amongst the mothers of children in the rampant caries group. They might have been unwilling to admit to practices they knew or suspected to be harmful to the teeth, such as excessive eating of sweets. Conversely they might be inclined to exaggerate their claims with regard to breast feeding or oral hygiene habits. As far as possible questions in the interview were posed in an oblique manner.

Children were considered as never breast fed if the practice was discontinued before the end of the first month, as it was assumed that it was never adequately established. A prolonged 'comforter' bottle was taken 


\section{INVESTIGATION OF RAMPANT CARIES- DECIDUOUS DENTITION}

(I) Name, date of birth, age

(2) Teeth affected (chart)

(3) Age at which deciduous incisors first erupted

(4) Condition of teeth on eruption

(5) Dietary History

(a) Breast-feeding

(b) Bottle-feeding

Age terminated

Age commenced

Age terminated

Substances in bottle

(c) Comforters

(i) Prolonged comforter bottle) Nature of sub-

(ii) Hollow feeder

(iii) Dipped dummy

(d) Vitamin supplements

(e) Other sources of carbohydrate excess

(6) Oral hygiene habits (Tooth cleansing)

(7) Abnormality of:
(a) Pregnancy
(b) Labour and delivery
(c) Infancy and early childhood

FIG. 2.-Standardized form for interview and examination.

to be the regular daily use of a feeding bottle after the end of the child's first year of life.

The mouth was examined with the aid of dental mirrors, under similar conditions of artificial light throughout. In addition to assessing the presence or absence of rampant caries as previously defined, the number of decayed, extracted, or filled teeth (d.e.f.) was recorded for each child, as the mean d.e.f. gives a standard of comparison between the groups, which is generally accepted in epidemiological surveys of dental disease. For both these purposes the diagnosis of decay was taken to be a visible cavity in which it was considered that the dentine was involved. No attempt was made to use dental explorers to determine "sticky" pits and fissures on occlusal surfaces, or to radiograph the teeth for approximal decay, as many of the children were too young to permit these methods of examination.

The two groups of 100 children examined will for brevity be referred to as the study (rampant caries) and control (welfare centre) groups. Each group has been subdivided into two smaller subgroups on an age basis of 1-3 years and 3-5 years.

\section{Results}

The composition of the sample, the percentage of children affected by rampant caries, and the mean number of d.e.f. teeth per child for each subgroup and for the total groups are shown in Table $I$. There was a significant difference ( $p<0.01$ ) between the mean d.e.f. prevalences in the study and control groups. It should be noted that $12 \%$ of the children in the control group were found to have rampant caries, which indicates the prevalence of the condition in this group of dentally unselected preschool children.

There were no significant differences between the groups either in the mean age of eruption of anterior teeth or in the proportion of children reported by their mother to have defective teeth on eruption ( $p>0 \cdot 05)$. On clinical examination only one child in the study group showed evidence of enamel hypoplasia while in the control group this was not seen in any of the children.

Breast feeding, abnormalities, and ill health. Table II shows proportion of children never breast fed, those breast fed for periods of up to 3 months, and those for periods over 3 months. There were no significant differences between the two groups ( $p>0 \cdot 05)$.

The proportions of cases with a history of abnormalities of pregnancy, labour, and delivery of the mothers, and illnesses during infancy and early childhood, including prematurity of birth, for all children in both groups are also shown in Table II. Over-all significance is just reached $(p=0.05)$ in assessing the differences between the study and control groups for maternal abnormality during pregnancy, labour, and delivery. These abnormali-

TABLE I

Age, Sex, Percentage with Rampant Caries, and Mean d.e.f. Values in Study and Control Groups

\begin{tabular}{|c|c|c|c|c|c|c|c|}
\hline & \multicolumn{2}{|c|}{ Group } & \multirow{2}{*}{ No. } & \multirow{2}{*}{ Male } & \multirow{2}{*}{ Female } & \multirow{2}{*}{$\begin{array}{c}\text { Children with } \\
\text { Rampant } \\
\text { Caries (\%) }\end{array}$} & \multirow{2}{*}{$\begin{array}{l}\text { Mean No. of d.e.f. } \\
\text { Teeth }( \pm \text { S.E. })\end{array}$} \\
\hline & Age (yr.) & Mean Age (yr.) & & & & & \\
\hline \multirow[t]{2}{*}{ Study } & $\begin{array}{r}1-3 \\
3-5 \\
\end{array}$ & $\begin{array}{c}24 / 12 \\
4\end{array}$ & $\begin{array}{l}44 \\
56\end{array}$ & $\begin{array}{l}21 \\
28 \\
\end{array}$ & $\begin{array}{l}23 \\
28 \\
\end{array}$ & $\begin{array}{l}44 \\
56 \\
\end{array}$ & $\begin{array}{r}8.3 \pm 0.73 \\
12.5 \pm 0.55 \\
\end{array}$ \\
\hline & Total & $\ldots$ & 100 & 49 & 51 & 100 & $10.6 \pm 0.49$ \\
\hline \multirow[t]{2}{*}{ Control } & $\begin{array}{l}1-3 \\
3-5\end{array}$ & $\begin{array}{c}22 / 12 \\
311 / 12\end{array}$ & $\begin{array}{l}54 \\
46\end{array}$ & $\begin{array}{l}27 \\
27\end{array}$ & $\begin{array}{l}27 \\
19\end{array}$ & $\begin{array}{l}3 \\
9\end{array}$ & $\begin{array}{l}0.4 \pm 0.25 \\
3.2 \pm 0.59\end{array}$ \\
\hline & Total & . & 100 & 54 & 46 & 12 & $1 \cdot 7 \pm 0 \cdot 33$ \\
\hline
\end{tabular}


TABLE II

Breast-feeding and History of Abnormality or Illness in Mother and Child in Study and Control Groups between 1 and 5 years of age

\begin{tabular}{|c|c|c|c|c|c|c|c|c|}
\hline & & & \multirow{2}{*}{ No. } & \multicolumn{3}{|c|}{ Breast-fed ( $\%)$} & \multirow{2}{*}{$\begin{array}{c}\text { Abnormal } \\
\begin{array}{c}\text { Pregnancy, Labour, } \\
\text { or Delivery }(\%)\end{array}\end{array}$} & \multirow{2}{*}{$\begin{array}{l}\text { Illness of Child } \\
\text { Including } \\
\text { Prematurity }(\%)\end{array}$} \\
\hline & & & & Never & $<3$ months & $>3$ months & & \\
\hline Study & & .. & Age $\quad 100$ yr. & 44 & 22 & 34 & 44 & 44 \\
\hline Control & $\ldots$ & . & Age $\begin{array}{l}100 \\
1-5 \\
\text { yr. }\end{array}$ & 48 & 24 & 28 & 30 & 17 \\
\hline
\end{tabular}

ties include toxaemia (10 study, 5 control), hyperemesis gravidarum (6 study, 3 control), anaemia (7 study, 4 control), ante-partum haemorrhage ( 1 study, 1 control), other serious maternal illness or operation (3 study, 1 control), caesarean section (7 study, 5 control), forceps delivery (5 study, 10 control), breech presentations ( 2 study, 1 control), and twin births ( 3 study only).

However, there is a highly significant difference ( $p<0.01$ ) between the groups as regards the proportions showing illnesses of the child during infancy and early childhood, including prematurity of birth. These illnesses were mainly of a mild nature and included exanthematous fevers, infantile gastro-enteritis, upper respiratory tract infections, and minor surgery. 2 cases in the study group had suffered serious illness, one meningitis complicated by hydrocephalus and mental retardation, and the other congenital ectodermal dysplasia of the hidrotic type. Only one case in the control group had a serious illness which was acyanotic congenital heart disease.

Comforters and vitamin supplements. Table III shows the proportions of children (a) still on the bottle at the time of examination, (b) using comforter feeding bottles, (c) using comforters of all types, (d) using sweetened comforters, (e) receiving vitamin supplements. In all cases except (e), there was a significant difference in proportions between study and control groups $(p<0 \cdot 01)$. Of children who had ceased the practice of comforter bottle feeding, the mean age of cessation was 2 years 2 months in the study group and 1 year 10 months in the control group. The times of the day and night at which the comforter was given were similar in both groups.

The contents of the bottles were also investigated. Fresh cows' milk was used in $48 \%$ of children in the study and $82 \%$ of cases in the control group. The remainder used either reconstituted dried milk preparations, diluted fruit juices, or fruit syrups. In the study group $85 \%$ of the bottles were sweetened by the addition of sugar (sucrose) against $91 \%$ in the control group, but this was to some extent counterbalanced by the much higher percentage of pre-sweetened dried milk preparations and fruit syrups found in the study group.

If sugar added by the manufacturers is taken into account, $93 \%$ of the bottles in the study group were sweetened compared with $98 \%$ in the control group.

Of the children in the study group, $21 \%$ had been given sweetened hollow feeders or dummies compared with $13 \%$ in the control group. The main sweetening agent in both groups was undiluted rose hip syrup. Honey, golden syrup, sugar, and other fruit syrups were used in the remaining cases.

With regard to vitamin supplements, though the

TABLE III

History of Bottle-feeding, Comforters, and Vitamin Supplements in Study and Control Groups

\begin{tabular}{|c|c|c|c|c|c|c|c|}
\hline Group & $\begin{array}{l}\text { Age-group } \\
\text { (yr.) }\end{array}$ & No. & $\begin{array}{c}\text { Percentage } \\
\text { Still } \\
\text { on } \\
\text { Bottle }\end{array}$ & $\begin{array}{l}\text { Percentage } \\
\text { Using } \\
\text { Comforter } \\
\text { Bottles }\end{array}$ & $\begin{array}{l}\text { Percentage } \\
\text { Using } \\
\text { Comforters } \\
\text { (all types) }\end{array}$ & $\begin{array}{c}\text { Percentage } \\
\text { Using } \\
\text { Sweetened } \\
\text { Comforters }\end{array}$ & $\begin{array}{l}\text { Percentage } \\
\text { Using } \\
\text { Vitamin } \\
\text { Supplements }\end{array}$ \\
\hline \multirow[t]{2}{*}{$\begin{array}{lll}\text { Study } & \ldots & \ldots\end{array}$} & $\begin{array}{l}1-3 \\
3-5\end{array}$ & $\begin{array}{l}44 \\
56\end{array}$ & $\begin{array}{l}56 \cdot 8 \\
21 \cdot 4\end{array}$ & $\begin{array}{l}90 \cdot 9 \\
83.9\end{array}$ & $\begin{array}{l}95 \cdot 5 \\
85 \cdot 7\end{array}$ & $\begin{array}{l}88 \cdot 6 \\
76 \cdot 8\end{array}$ & $\begin{array}{r}100 \cdot 0 \\
85 \cdot 7\end{array}$ \\
\hline & Total & 100 & $37 \cdot 0$ & $87 \cdot 0$ & $90 \cdot 0$ & $84 \cdot 0$ & $92 \cdot 0$ \\
\hline \multirow[t]{2}{*}{ Control } & $\begin{array}{l}1-3 \\
3-5\end{array}$ & $\begin{array}{l}54 \\
46\end{array}$ & $\begin{array}{r}24 \cdot 1 \\
8 \cdot 7\end{array}$ & $\begin{array}{l}53 \cdot 7 \\
60 \cdot 7\end{array}$ & $\begin{array}{l}59 \cdot 3 \\
65 \cdot 2\end{array}$ & $\begin{array}{l}59 \cdot 3 \\
63 \cdot 0\end{array}$ & $\begin{array}{l}81 \cdot 5 \\
84 \cdot 8\end{array}$ \\
\hline & Total & 100 & $17 \cdot 0$ & $57 \cdot 0$ & $62 \cdot 0$ & $61 \cdot 0$ & $83 \cdot 0$ \\
\hline
\end{tabular}


over-all difference between the groups is not significant, it does reach a significant level in the younger children ( $p<0.01)$, greater usage being found in the study group. These supplements consist in the main of vitamin C-containing syrups and juices, such as rose hip syrup, concentrated orange juice, and blackcurrant syrup. The remainder is made up of vitamin concentrates which include sweetened malt and cod-liver oil extracts, which account for only $16(16 \%)$ cases in the study group and $5(5 \%)$ cases in the control, $6 \%$ of the study group and 3\% of the control group having this form of vitamin supplement alone.

Eating between meals, and oral hygiene. There were no significant differences between the two groups with regard to the excessive eating of fermentable carbohydrates between meals or in the oral hygiene habits practised by the child ( $p>0.05)$. $79 \%$ of the study group, and $77 \%$ of the control group admitted to an excess of fermentable carbohydrates between meals. This included sweets, chocolates, ice-cream, ice-lollies, fruit squash, carbonated beverages, biscuits, and cakes. $85 \%$ of the study cases and $72 \%$ of the control group claimed to be cleaning or having their teeth cleaned with a tooth-brush. The mean age for the onset of this practice was 1 year 6 months in the study group and 1 year 10 months in the control group. Tooth cleansing was claimed to be carried out for a mean of 1.5 times per day per case in both the study and control groups.

\section{Discussion}

Aetiology. The most significant factor in the production of rampant caries in the groups of children under investigation was the use of sweetened comforters. This is in agreement with other work on the subject, previously quoted. The anatomical distribution of the carious lesions about the dentition indicated a predominantly local factor which had its initial effect on the maxillary incisor teeth.

It is evident, however, that the use of comforters, though a significant factor, does not in every case produce the disease. $34 \%$ of children in the control group showed no evidence of caries despite the prolonged use of comforter bottles, and $5 \%$ of children were unaffected, though they had regularly sucked sweetened hollow feeders or dummies for periods varying from 5 to 22 months after the eruption of their anterior teeth.

It is interesting to speculate on the reasons why a proportion of the comforter suckers escaped caries. The substance placed in a comforter bottle is no doubt of some importance. The higher proportion of bottles in the control group contained cows' milk, while that in the study group contained presweetened powdered milk or fruit syrups. The study group, too, used the comforters for a longer time than the control group and a much higher proportion of this group was still on the bottle at the time of examination. It also seems likely that individual resistance to the disease may have been a factor in these cases. Conversely it might be argued that those who did contract the disease were predisposed in some way (Sognnaes and White, 1940; Mansbridge, 1959).

It is difficult to assess the exact role of predisposing factors in the aetiology of rampant caries of the deciduous dentition. There appear to be several ways in which such factors might operate. A metabolic upset of the foetus or infant, which might accompany maternal illness during pregnancy; prematurity or infantile disease might lead to changes in the surface structure of the deciduous enamel (Sheldon, Bibby, and Bales, 1945; Stein, 1947), which may in turn predispose it to dental caries (Rosenzweig and Sahar, 1962). In this survey only one case in the study group and none in the control group demonstrated enamel hypoplasia which could be detected by clinical observation.

Systemic disturbances during infancy and early childhood might operate in another way, by bringing about changes in the oral environment, such as the decreased salivation that accompanies periods of pyrexia or dehydration, and this might equally well predispose the child to an increased caries prevalence.

One other and less subtle way in which these predisposing factors might operate is in the overindulgence of sick children by their parents with sweetened comforters, fruit juices, and syrups, which may be effective in increasing caries prevalence by purely local means within the oral cavity.

There seems little doubt, however, that in this country local factors are all important in the causation of rampant caries in the deciduous dentition and that the factor principally involved is the prolonged sucking of sweetened feeding bottles, hollow feeders, and dummies. The use of comforters to pacify children is an ancient custom known to the Romans (Gorelick, 1955), one of the earliest recorded accounts of the use of a sweetened comforter being given by Struve (1801). The type of comforter employed appears to be subject to changes in social habit with time, and whereas in London in the 1920's the dummy was in vogue (Pitts, 1927), the most recent fashion has been for the feeding bottle, especially of the light plastic variety.

The sweetening is almost invariably sugar 
(sucrose), and this is probably the main agent in producing rampant caries of the deciduous dentition, the feeding bottle or its equivalent, acting as the means by which a continuous slow ingestion into the mouth is achieved. This effect is magnified if, as is often the case, the child continues to suck on the bottle during sleep when the normal salivary output is considerably reduced (Jenkins, 1960) and local factors favouring stagnation are increased.

While sucrose may be the main aetiological agent promoting this disease, its effect is further enhanced by the simultaneous ingestion of highly acid fruit juices and syrups, the erosive quality of which has been adequately demonstrated by Holloway, Mellanby, and Stewart (1958) and Hartles and Wagg (1962). It is possible that when these substances are frequently ingested erosion is the primary enamel change which precedes rampant caries.

It also seems likely that in the predisposed child the frequent ingestion of these fruit juices and syrups by spoon or cup over the period of several years subsequent to the eruption of the teeth may result in rampant decay, especially if these substances are taken undiluted.

Of the other factors investigated in this study, none proved to be of statistical significance in relation to rampant caries of the deciduous dentition. This includes breast feeding, the excessive consumption of fermentable carbohydrate, mainly sugar, between meals, and the oral hygiene habits practised by the child. The fact that a slightly higher percentage of parents in the study group claimed greater credit for the oral hygiene habits of their children possibly reflects an inaccuracy of memory occasioned by a sense of guilt. It is well known also that questioning the parent about sweet-eating habits of the child is not a reliable method of assessment. Over three-quarters of the children in both groups were consuming excessive amounts of fermentable carbohydrate between meals; this should not pass without comment, for it almost certainly reflects a basic imbalance in the diet of all these children.

The recent work of Hargreaves (1964) shows a direct relation between caries susceptibility in the deciduous and permanent dentitions in this country, and highlights the problem of rampant decay of the deciduous dentition. If measures are not taken to prevent this disease in the deciduous dentition it may be reflected by a similar situation in the permanent dentition later in childhood or adolescence.

\section{Summary}

An attempt has been made to establish the aetiological factors involved in 100 pre-school children presenting with rampant caries of the deciduous dentition by comparing them with a similar number of controls.

The results suggest that there are two main factors controlling the incidence of rampant caries in the pre-school population. One is a predisposition to the disease, which may be partially determined by abnormality of pregnancy, labour, or delivery, by prematurity, or by recurrent minor illness during the early years of life. The other, more important factor, is due to changes in the oral environment brought about by the frequent and prolonged ingestion of milk, fruit juices, or syrups which have been sweetened by the addition of sugar. The mode of ingestion of these substances appears to be causally related to the caries prevalence, and in this respect, the prolonged sucking of sweetened comforter feeding bottles, hollow feeders, and dummies seem to be extremely significant.

We should like to record our grateful thanks to $\mathrm{Mr}$. R. R. Stephens, Senior Lecturer and Head of the Department of Children's Dentistry, Institute of Dental Surgery, Eastman Dental Hospital, for his encouragement; and to Dr. W. G. Harding and Miss K. F. Symonds for their great help in enabling us to examine the control children.

REFERENCES

Beltrami, G., and Romieu, M. (1939). La mélanodontie infantile. Rev. Stomat. (Paris), 41, 433.

Gorelick, L. (1955). On the use of pacifiers in preventing malocclusion. N.Y. St. dent. F., 21, 3.

Hargreaves, J. A. (1964). The problem of caries in child dental health. Brit, dent. F., 116, 386.

Harries, E. H. R. (1911). "Comforter" caries. Lancet, 2, 1327.

Hartles, R. L., and Wagg, B. J. (1962). Erosive effect of drinking fluids on the molar teeth of the rat. Arch. oral Biol., 7, 307.

Holloway, P. J., Mellanby, M., and Stewart, R. J. C. (1958). Fruit drinks and tooth erosion. Brit. dent. F., 104, 305.

James, P. M. C., Parfitt, G. J., and Falkner, F. (1957). A study of the aetiology of labial caries of the deciduous incisor teeth in small children. ibid., 103, 37.

Jenkins, G. N. (1960). Physiology of the Mouth, p. 241. Blackwell Scientific Publications, Oxford.

Mansbridge, J. N. (1959). Heredity and dental caries. f. dent. Res., 38, 337.

Pitts, A. T. (1927). Some observations on the occurrence of caries in very young children. Brit. dent. F., 48, 197.

Robinson, S., and Naylor, S. R. (1963). The effects of late weaning on the deciduous incisor teeth. ibid., 115, 250.

Rosenzweig, K. A., and Sahar, M. (1962). Enamel hypoplasia and dental caries in the primary dentition of prematuri. ibid., 113, 279.

Sheldon, M., Bibby, B. G., and Bales, M. S. (1945). The relationship between microscopic enamel defects and infantile debilities. f. dent. Res., 24, 109.

Sognnaes, R. F., and White, R. L. (1940). Oral conditions of children in relation to state of general health and habits of life. Amer. F. Dis. Child., 60, 283.

Stein, G. (1947). Enamel damage of systemic origin in premature birth and diseases of early infancy. Amer. F. Orthodont., 33, 831.

Struve, C. A. (1801). A Familial Treatise on the Physical Education of Children During the Early Period of their Lives, p. 271. (Translated from the German.) Murray and Highley, London.

Syrrist, A., and Selander, P. (1953). Some aspects on comforters and dental caries. Odont. T., 61, 237. 